\title{
DETERMINAÇÃO DO BORO, SOLÚVEL EM ÁCIDO, EM FERTILIZANTES *
}

\author{
J. C. Alcarde ** \\ R. A. CATANI ** \\ O. S. SOUZA $* * *$
}

\section{RESUMO}

\begin{abstract}
O presente trabalho relata os estudos desenvolvidos sobre alguns aspectos do método volumétrico de determinação do boro, solúvel em ácido, em fertilizantes. Foram objeto de estudos a influência dos ions amônio e fosfato e suas consequentes eliminações, a possibilidade da redução da massa de manitol necessária para a titulação, face a mudança do $\mathrm{pH}$ do ponto final e a precisão e a exatidão do método.

Os resultados permitiram estabelecer que $6,0 \mathrm{~g}$ de manitol são suficientes para a referida determinação pelo método proposto. A influência do íon amônio é evitada pela fervura da solução alcalina por $30 \mathrm{minu}$ tos e o ânion sulfato influe na precipitação do fosfato com $\mathrm{Pb}^{2+}$, sendo por isso, necessário $1 \mathrm{ml}$ da solução de $\mathrm{Pb}$ ( $\mathrm{NO}$ ) a $10 \%$ pará cada $1 \%$ de $\mathrm{P}_{2} \mathrm{O}_{5}$ da amostra para a completa precipitação do fósfato. $\mathrm{O}$ método proposto é dotado de adequada precisão e exatidão.
\end{abstract}

\section{INTRODUÇÃO}

Dentre os micronutrientes adicionados às misturas de fertilizantes figura o boro, que, juntamente com o zinco, ocupa posição de destaque.

Nos fertilizantes o boro é mais comumente adicionado sob a forma de borax (ortoborato de sódio $-\mathrm{Na}_{2} \mathrm{~B}_{4} \mathrm{O}_{7} \cdot 10 \mathrm{H}_{2} \mathrm{O}$ ) ou ácido bórico $\left(\mathrm{H}_{3} \mathrm{BO}_{3}\right)$, materiais prontamente solúveis em água. No entanto, diversos outros materiais boratados, mas pouco solúveis em água, também são empregados (BERGER \& PRATT, 1963). Além disso há a possibilidade de formação de boratos de cálcio e borofosfatos pouco solúveis em água durante $\mathrm{o}$ armazenamento (TAYLOR, 1949).

\footnotetext{
* Entregue para publicação em 3-1-1973.

** Departamento de Química da Escola Superior de Agricultura "Luiz de Queiroz".

*** Bolsista da MANAH.
} 
Nos fertilizantes o boro é normalmente determinado sob duas formas: solúvel em água e solúvel em ácido (OFFICIAL METHODS OF ANALYSIS OF THE A.O.A.C., 1970). Para a determinação do boro em fertilizantes, recentemente, tem sido sugeridos métodos físico-químicos, os quais, no entanto, carecem ainda de estudos mais aprimorados (SCHALL, 1969; RUND, 1970 e 1971). O método mais empregado para a referida determinação é o volumétrico, baseado na titulação do ácido bórico ou borato com solução padronizada de $\mathrm{NaOH}$, em presença de manitol (BORLAND, BROWNLIE \& GODDEN, 1967; OFFICIAL METHODS OF ANALYSIS OF THE A.O.A.C., 1970; ALCARDE, CATANI \& KROLL, 1971).

Quanto a determinação do boro, solúvel em água, em fertilizantes, ALCARDE, CATANI \& KROLL (1971) apresentaram algumas modificações nas técnicas recomendadas e conseguiram reduzir a massa de manitol a ser empregada de $20,0 \mathrm{~g}$ para 6,0 g.

Esses resultados levaram ALCARDE, CATANI \& SOUZA (1972) a estudar a quantidade de manitol necessária para a titulação do ácido bórico com solução padronizada de $\mathrm{NaOH}$, visando a determinação do boro, solúvel em ácido, em fertilizantes. Os resultados obtidos com soluçeõs puras mostraram que existe possibilidade de se reduzir de $20,0 \mathrm{~g}$ para $5,0 \mathrm{~g}$ a massa de manitol na citada determinação, desde que se use o $\mathrm{pH} 8,0$ para o ponto final da titulação e se proceda a eliminação do íon amônio.

Assim, constituiu-se no objetivo do presente trabalho a adaptação desses resultados à determinação do boro, solúvel em ácido, em fertilizantes. Para tanto foram estudadas a influência dos ânions fosfato e amônio e suas consequentes eliminações, modificadas algumas das técnicas recomendadas e finalmente avaliada a precisão e exatidão do método proposto.

\section{MATERIAL E MÉTODOS}

\section{Material}

O material constou de duas misturas de fertilizantes, caracterizadas como $M_{1}$ e $M_{2}$, preparadas em laboratório a partir de fertilizantes simples comerciais. O preparo das misturas foi feito colocando-se todos os componentes num gral de porcelana, onde se procedeu a trituração e homogeneização. $O$ quadro 1 apresenta a composição porcentual de cada mistura. A fórmula aproximada da mistura $M_{1}$ é 5,5-17,0-12,0 e da mistura $M_{2}$ é 3,5-20,0-12,0. 
QUADRO 1. - Composição porcentual das misturas preparadas em laboratório.

\begin{tabular}{l|l|l}
\hline \multirow{2}{*}{ Componentes } & \multicolumn{2}{|c}{ Misturas } \\
\cline { 2 - 3 } & $\mathbf{M}_{2}$ & $\mathbf{M}_{1}$ \\
\hline Superfosfato simples & 20 & 30 \\
Superfosfato triplo & 30 & 30 \\
Cloreto de potássio & 20 & 20 \\
Salitre do Chile & 10 & 10 \\
Sulfato de amônio & 20 & 10 \\
\hline
\end{tabular}

\section{Reativos}

Dos reativos empregados merecem menção os seguintes:

Solução de $\mathrm{H}_{3} \mathrm{BO}_{3} \mathbf{0 , 1 0 0} \mathbf{N}$. Dissolver $3,0918 \mathrm{~g}$ de $\mathrm{H}_{3} \mathrm{BO}_{3}$ p.a., seco em estufa a $40^{\circ} \mathrm{C}$ por 4 horas, em água destilada, transferir para balão volumétrico de $500 \mathrm{ml}$ e completar o volume.

Solução de $\mathrm{NaOH}$ aproximadamente $0,025 \mathrm{~N}$ livre de $\mathrm{CO}_{2}$. Ferver 3 litros de água destilada por 20 minutos, com a finalidade de remover o $\mathrm{CO}_{2}$, esfriar rapidamente e transferir para um frasco de plástico fechado com um dispositivo contendo "ascarite" para evitar a entrada do $\mathrm{CO}_{2}$ do ar. Juntar $7,5 \mathrm{ml}$ do sobrenadante de uma solução $10 \mathrm{~N}$ de $\mathrm{NaOH}$ (livre de $\mathrm{Na}_{2} \mathrm{CO}_{3}$ ) e agitar.

Ligar esse frasco de plástico a uma bureta na qual também deve ser adaptado um dispositivo contendo "ascarite" para evitar a entrada do $\mathrm{CO}_{2}$ do ar. Padronizá-la.

Solução de $\mathrm{NaOH}$ aproximadamente $0,5 \mathrm{~N}$, livre de $\mathrm{CO}_{2}$. Proceder de maneira idêntica ao preparo da solução de $\mathrm{NaOH} 0,025 \mathrm{~N}$, livre de $\mathrm{CO}_{2}$, já descrito, apenas que se deve ferver apenas 0,5 litro de água destilada e usar $25 \mathrm{ml}$ do sobrenadante da solução de $\mathrm{NaOH} 10 \mathrm{~N}$ (livre de $\mathrm{Na}_{2} \mathrm{CO}_{3}$ ).

\section{Métodos}

Padronização da solução de $\mathrm{NaOH} \quad 0,025 \mathrm{~N}$, livre de $\mathrm{CO}_{2}$

1. Transferir três vezes $10 \mathrm{ml}$ da solução de $\mathrm{H}_{3} \mathrm{BO}_{3} 0,100 \mathrm{~N}$ para copos de $250 \mathrm{ml}$, acrescentar $3 \mathrm{~g}$ de $\mathrm{NaC} 1$ e 5 gotas de solução 
de vermelho de metila a $0,1 \%$. Acidificar com solução de HC1 $(1+5)$ até obter a cor vermelha do indicador e ferver por 5 minutos para expelir o $\mathrm{CO}_{2}$. Esfriar a temperatura ambiente.

Neutralizar a solução grosseiramente até obter a cor rósea do indicador, com solução de $\mathrm{NaOH} 0,5 \mathrm{~N}$, livre de $\mathrm{CO}_{2}$. Levar os copos para o conjunto de titulação, que é constituido de um potenciômetro, de um agitador magnético e da bureta contendo a solução de $\mathrm{NaOH} \quad 0,025 \mathrm{~N}$, livre de $\mathrm{CO}_{2}$.

3. Mergulhar os eletrodos na solução, ligar o agitador e ajustar o pH a exatamente 6,30 pela adição de solução de $\mathrm{NaOH} 0,025 \mathrm{~N}$, livre de $\mathrm{CO}_{2}$ ou solução de $\mathrm{HC1} 0,02 \mathrm{~N}$, conforme o caso.

4. Adicionar $6 \mathrm{~g}$ de manitol e titular com a solução $\pm 0,025 \mathrm{~N}$ de $\mathrm{NaOH}$ até o pH da solução ser exatamente 8,0. Anotar o volume gasto. Desenvolver uma prova em branco.

\section{Determinação do boro, solúvel em ácido, em fertilizantes.}

1. Pesar $1,000 \mathrm{~g}$ da amostra finamente moida e transferir para copo de $250 \mathrm{ml}$. Juntar $50 \mathrm{ml}$ de água destilada e $6 \mathrm{ml}$ de solução de HC1 $6 \mathrm{~N}$ destilado. Aquecer a ebulição e conservar quente por $5-10$ minutos.

2. Conservando a solução quente, mas sem ferver, proceder ao seguinte tratamento:

a) adicionar $1 \mathrm{ml}$ de solução de $\mathrm{Pb}\left(\mathrm{NO}_{3}\right)_{2}$ a $10 \%$ para cada $1,0 \%$ de $\mathrm{P}_{2} \mathrm{O}_{5}$ da amostra.

b) juntar, vagarosamente, solução de $\mathrm{Na}_{2} \mathrm{CO}_{3}$ a $12 \%$ até a solução aproximar-se da neutralidade (esse ponto é identificado pela formação de um precipitado branco junto do material sólido insolúvel).

c) Juntar 3 gotas de solução alcoolica de fenolftaleina a $1 \%$ e continuar a adição de solução de $\mathrm{Na}_{2} \mathrm{CO}_{3}$ a $12 \%$ até a solução tornar-se rosada. Manter a solução quente, mas sem ferver por 15 minutos, agitando esporadicamente.

3. Filtrar por papel S\&S 589, faixa branca, recebendo o filtrado num copo de $400 \mathrm{ml}$, lavando o copo e o filtro com 5 porções de $10 \mathrm{ml}$ de solução de $\mathrm{Na}_{2} \mathrm{CO}_{3}$ a $0,25 \%$ quente.

4. Acrescentar água destilada suficiente para fazer um volume de aproximadamente $200 \mathrm{ml}$. Acrescentar 3 pedras "boileezers" e ferver lentamente a solução por 30 minutos com o copo aberto para eliminar $\mathrm{NH}_{3}$.

5. Adicionar solução de $\mathrm{HC} 10,5 \mathrm{~N}$, gota a gota, até desapa- 
recer a cor rosada da fenolftaleina. Juntar 5 gotas de solução de vermelho de metila a $0,1 \%$ e continuar a adição do ácido até a obtenção da cor rósea do indicador. Acrescentar 0,5 ml de excesso. Diluir a aproximadamente $150 \mathrm{ml}$ com água destilada.

6. Ferver vagarosamente por 5 minutos para eliminar $\mathrm{CO}_{2} \mathrm{e}$ esfriar a temperatura ambiente.

7. Neutralizar a solução grosseiramente com solução de $\mathrm{NaOH}$ $0,5 \mathrm{~N}$, livre de $\mathrm{CO}_{2}$, até obter a cor alaranjada do vermelho de metila e levar o copo para o conjunto de titulação, mergulhando o agitador e os eletrodos.

8. Ligar o agitador e ajustar o $\mathrm{pH}$ a exatamente 6,30, pela adição de solução de $\mathrm{NaOH} 0,025 \mathrm{~N}$, livre de $\mathrm{CO}_{2}$, ou de $\mathrm{HC1} 0,02 \mathrm{~N}$, conforme o caso. Quando adequadamente ajustado o $\mathrm{pH}$ deve ser invariável.

9. Adicionar $6,0 \mathrm{~g}$ de manitol, esperar dissolver e titular com a solução padronizada de $\mathrm{NaOH}( \pm 0,025 \mathrm{~N})$, livre de $\mathrm{CO}_{2}$, até o $\mathrm{pH}$ da solução ser exatamente 8,0. Anotar o volume gasto. Desenvolver uma prova em branco.

\section{RESULTADOS OBTIDOS E DISCUSSÃO}

\section{Eliminação do ion $\mathrm{NH}_{4}{ }^{+}$.}

De acorcio com ALCARDE, CATANI \& SOUZA (1972), a massa de manitol necessária para a titulação do ácido bórico pode ser reduzida, desde que o pH do ponto final seja 8,0. Nestas condições o íon amônio passa a influir na determinação em aprêço, o que não ocorreria se o ponto final da titulação fosse no $\mathrm{pH}=6,30$, como demonstram os dados do quadro 2, os quais foram obtidos titulando-se o $\mathrm{H}_{3} \mathrm{BO}_{3}$ em presença de quantidades variáveis de $\mathrm{NH}_{4}+\left(\mathrm{NH}_{4} \mathrm{C} 1\right)$, procedendo-se conforme descrito na padronização da solução de $\mathrm{NaOH} \pm 0,025 \mathrm{~N}$.

Para eliminação do ion $\mathrm{NH}_{4}{ }^{+}$foi adotada a técnica da fervura da solução alcalina, técnica essa adotada na determinação volumétrica do boro solúvel em água (OFFICIAL METHODS OF ANALYSIS OF THE A.O.A.C., 1965 e 1970; ALCARDE, CATANI \& KROLL, 1971), onde a solução é fervida por 1 hora. Usando soluções puras determinou-se o boro em presença de $200 \mathrm{mg}$ do íon $\mathrm{NH}_{4}{ }^{+}$, conforme descrito na determinação do boro, solúvel em ácido, em fertilizantes, (no caso foram eliminadas as operações desnecessárias), 
QUADRO 2. - Titulação de $10 \mathrm{ml}$ de solução de $\mathrm{H}_{3} \mathrm{BO}_{3} \quad 0,100 \mathrm{~N}$ com solução de $\mathrm{NaOH}$, em presença do ion $\mathrm{NH}_{4}^{+}$

\begin{tabular}{c|c|c}
\hline \multirow{2}{*}{$\mathrm{mg} \mathrm{NH}_{4}^{+}$adicionado } & \multicolumn{2}{|c}{$\mathrm{ml} \mathrm{sol.} \mathrm{NaOH} \pm 0,025 \mathrm{~N}$ gastos na tit. } \\
\cline { 2 - 3 } & ponto final $\mathrm{pH}=6,3$ & ponto final $\mathrm{pH}=8,0$ \\
\hline 0 & 38,7 & 43,9 \\
20 & 38,8 & 48,0 \\
& 38,6 & 59,8 \\
\hline
\end{tabular}

somente que no item 4 a solução foi fervida por 15, 30 e 60 minutos. Os resultados acham-se descritos no quadro 3.

QUADRO 3. - Determinação do boro, em soluções puras, na presença do íon $\mathrm{NH}_{4}^{+}$, após fervura da solução alcalina por diversos períodos de tempo.

\begin{tabular}{c|c|c|c|c}
\hline \multirow{2}{*}{$\begin{array}{c}\text { ml solução } \\
\mathrm{H}_{3} \mathrm{BO}_{3} 0,100 \mathrm{~N}\end{array}$} & $\begin{array}{c}\text { mg NH } \\
\text { adicion. }\end{array}$ & \multicolumn{2}{|c|}{ ml de sol. $\mathrm{NaOH} \pm 0,025 \mathrm{~N}$ gastos na titul. } \\
\cline { 3 - 5 } & $\begin{array}{c}\text { fervura: } \\
15 \mathrm{~min} .\end{array}$ & $\begin{array}{c}\text { fervura: } \\
30 \mathrm{~min} .\end{array}$ & $\begin{array}{c}\text { fervura: } \\
60 \mathrm{~min} .\end{array}$ \\
\hline 0 & 0 & 0,6 & 1,3 & 2,0 \\
10 & 200 & 35,2 & 35,4 & 36,1 \\
10 & 35,9 & 35,3 & 36,0 \\
\hline
\end{tabular}

Portanto, os resultados mostram que 30 minutos de fervura são suficientes para eliminar $200 \mathrm{mg}$ de $\mathrm{NH}_{4}^{+}$.

\section{Eliminação do ânion fosfato}

Um sério interferente na determinação volumétrica do boro em fertilizantes é o ânion fosfato. Enquanto que na determinação do boro solúvel em água a eliminação desse ânion é feita precipitando-o com $\mathrm{Ba}^{2+}$, na determinação do boro solúvel em ácido, sua precipitação é feita com $\mathrm{Pb}^{2+}$ (OFFICIAL METHODS OF THE A.O.A.C., 1970). 
Para a eliminação do fosfato com $\mathrm{Pb}^{2+}$ é recomendado o uso de $1 \mathrm{ml}$ de solução de $\mathrm{Pb}\left(\mathrm{NO}_{3}\right)_{2}$ para cada $1,2 \%$ de $\mathrm{P}_{2} \mathrm{O}_{5}$ da amostra (OFFICIAL METHODS OF ANALYSIS OF THE A.O.A.C., 1970), relação essa comprovada por estudos desenvolvidos em soluções puras e cujos resultados estão descritos no quadro 4. Precedeu-se conforme descrito na determinação do boro, solúvel em ácido, em fertilizantes, usando porém solução padrão $0,100 \mathrm{~N}$ de $\mathrm{H}_{3} \mathrm{BO}_{3}$, solução padrão de $\mathrm{PO}_{4}^{3-}\left(\mathrm{KH}_{2} \mathrm{PO}_{4}\right.$, contendo $20 \mathrm{mg}$ de $\mathrm{PO}_{4}^{3-}$ por mililitro $)$ e $10 \mathrm{ml}$ de solução de $\mathrm{Pb}\left(\mathrm{NO}_{3}\right)_{2}$ a $10 \%$.

QUADRO 4. - Quantidade do ânion $\mathrm{PO}_{4}^{3-}$ eliminada por $10 \mathrm{ml}$ de solução de $\mathrm{Pb}\left(\mathrm{NO}_{3}\right)_{2}$ a $10 \%$, em soluções puras

\begin{tabular}{c|c|c|c|c}
\hline $\begin{array}{c}\text { ml sol. } \mathrm{H}_{3} \mathrm{BO}_{3} \\
0,100 \mathrm{~N} \text { adicion. }\end{array}$ & $\begin{array}{c}\mathrm{mg} \mathrm{H}_{3} \mathrm{BO}_{3} \\
\text { adicion. }\end{array}$ & $\begin{array}{c}\mathrm{mg} \mathrm{PO}_{4}^{3-} \\
\text { adicion. }\end{array}$ & $\begin{array}{c}\mathrm{ml} \mathrm{sol} \mathrm{NaOH} \\
0,0285 \mathrm{~N} \text { gastos } \\
\text { na titulação }\end{array}$ & $\begin{array}{c}\mathrm{mg}_{\mathrm{H}_{3} \mathrm{BO}_{3}} \\
\text { determinados }\end{array}$ \\
\hline 0 & 0,0 & 0 & 0,6 & - \\
0 & 0,0 & 160 & 0,7 & - \\
0 & 0,0 & 200 & 7,4 & $\mathbf{3 1 , 4}$ \\
5 & 30,9 & $\mathbf{1 6 0}$ & $\mathbf{1 8 , 4}$ & 43,4 \\
5 & 30,9 & 200 & 25,2 & $\mathbf{6 2 , 4}$ \\
10 & 61,8 & $\mathbf{1 6 0}$ & $\mathbf{3 6 , 0}$ & 74,4 \\
\hline
\end{tabular}

Os resultados mostram que $10 \mathrm{ml}$ da solução de $\mathrm{Pb}\left(\mathrm{NO}_{3}\right)_{2}$ a $10 \%$ conseguem eliminar $160 \mathrm{mg} \mathrm{PO}{ }_{4}^{3-}$, o que corresponde, na determinação em apreço, a relação de $1 \mathrm{ml}$ da citada solução para cada $1,2 \%$ de $\mathrm{P}_{2} \mathrm{O}_{5}$ na amostra.

$\mathrm{O}$ ânion sulfato não interfere na titulação do $\mathrm{H}_{3} \mathrm{BO}_{3}$, como mostram os dados do quadro 5. Neste estudo procedeu-se como descrito na padronização da solução de $\mathrm{NaOH} \pm 0,025 \mathrm{~N}$, acrescentando volumes variáveis da solução padrão de $\mathrm{Na}_{2} \mathrm{SO}_{4}$, contendo $10 \mathrm{mg}$ de SO ${ }_{4}^{2-}$ por mililitro. 
QUADRO 5. - Titulação de $\mathrm{H}_{3} \mathrm{BO}_{3}$ com solução padronizada de $\mathrm{NaOH}$, em presença de quantidades variáveis de $\mathrm{SO}_{4}^{2-}$

\begin{tabular}{c|c|c|c|c}
\hline \begin{tabular}{c|c}
$\mathrm{ml} \mathrm{de} \mathrm{sol} \mathrm{H}_{3} \mathrm{BO}_{3}$ \\
$0,100 \mathrm{~N}$ adicion.
\end{tabular} & $\begin{array}{c}\mathrm{mg}_{3} \mathrm{BO}_{3} \\
\text { adicion. }\end{array}$ & $\begin{array}{c}\mathrm{mg} \mathrm{de} \mathrm{SO}_{4}^{2-} \\
\text { presente }\end{array}$ & $\begin{array}{c}\mathrm{ml} \mathrm{sol} \mathrm{Na} \mathrm{OH} \\
0,0285 \mathrm{~N} \text { gastos } \\
\text { na tit. }\end{array}$ & $\begin{array}{c}\mathrm{mg}_{3} \mathrm{BO}_{3} \\
\text { det. }\end{array}$ \\
\hline 0 & 0,0 & 0 & 0,2 & - \\
10 & 61,8 & 0 & 35,3 & 61,8 \\
10 & 61,8 & 50 & 35,4 & 62,0 \\
10 & 61,8 & 100 & 35,4 & 62,0 \\
\hline
\end{tabular}

Porém, foi verificado que o ânion sulfato influe na precipitação

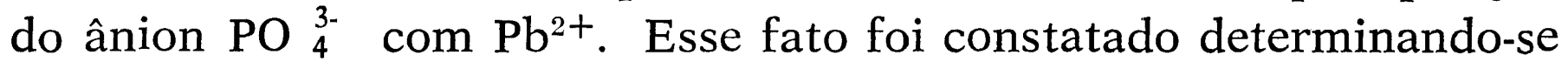
o $\mathrm{H}_{3} \mathrm{BO}_{3}$, em solução puras, na presença de $\mathrm{PO}_{4}^{3-}$ e $\mathrm{SO}_{4}^{2-}$, procedendo conforme descrito na determnação do boro solúvel em ácido, em fertilizantes. Neste estudo foram empregados $10 \mathrm{ml}$ de solução de $\mathrm{Pb}\left(\mathrm{NO}_{3}\right)_{2}$ a $10 \%$ e os resultados acham-se descritos no quadro 6.

QUADRO 6. - Determinação do $\mathrm{H}_{3} \mathrm{BO}_{3}$, em solução puras, na presença dos ânions $\mathrm{PO}_{4}^{3-}$ e SO ${ }_{4}^{2-}$, empregando $10 \mathrm{ml}$ de solução de $\mathrm{Pb}\left(\mathrm{NO}_{3}\right)_{2}$ a $10 \%$.

\begin{tabular}{|c|c|c|c|c|c|}
\hline $\begin{array}{c}\text { ml de sol. } \\
\mathrm{H}_{3} \mathrm{BO}_{3} \quad 0,100 \mathrm{~N} \\
\text { adicionado }\end{array}$ & $\begin{array}{l}\mathrm{mg}_{3} \mathrm{BO}_{3} \\
\text { adicionado }\end{array}$ & $\begin{array}{l}\operatorname{mg} \mathrm{PO}_{4}^{3-} \\
\text { adicionado }\end{array}$ & $\begin{array}{c}\operatorname{mg~SO}{ }_{4}^{2-} \\
\text { adicionado }\end{array}$ & $\begin{array}{l}\text { ml sol. } \mathrm{NaOH} \\
0,0285 \mathrm{~N} \text { gas- } \\
\text { tos da titulação }\end{array}$ & $\begin{array}{c}\mathrm{mg} \\
\mathrm{H}_{3} \mathrm{~B} \mathrm{O}_{3} \\
\text { determi- } \\
\text { nados }\end{array}$ \\
\hline 0 & 0,0 & 0 & 0 & 0,6 & - \\
\hline 0 & 0,0 & 0 & 100 & 0,6 & - \\
\hline 0 & 0,0 & 160 & 0 & 0,7 & - \\
\hline 0 & 0,0 & 160 & 100 & 1,6 & - \\
\hline 5 & 30,9 & 160 & 0 & 18,4 & 31,4 \\
\hline 5 & 30,9 & 160 & 100 & 18,8 & 32,1 \\
\hline 10 & 61,8 & 160 & 0 & 36,0 & 62,4 \\
\hline 10 & 61,8 & 160 & 100 & 37,1 & 64,3 \\
\hline
\end{tabular}


Assim, enquanto que $10 \mathrm{ml}$ de solução de $\mathrm{Pb}\left(\mathrm{NO}_{3}\right)_{2}$ a $10 \%$ foram suficientes para eliminar $160 \mathrm{mg}$ de $\mathrm{PO}_{4}^{3-}$ (resultados do quadro 2), essa quantidade de $\mathrm{Pb}\left(\mathrm{NO}_{3}\right)_{2}$ não foi suficiente para eliminar a mesma quantidade de $\mathrm{PO}_{4}^{3-}$ quando na presença de $100 \mathrm{mg}$ de $\mathrm{SO}_{4}^{2-}$.

Nestas condições e considerando que $12 \%$ de $\mathrm{SO}_{4}^{2-}$ é um teor razoável em fertilizantes, procurou-se estabelecer a relação entre a massa de $\mathrm{PO}_{4}^{3-}$ e o volume da solução de $\mathrm{Pb}\left(\mathrm{NO}_{3}\right)_{2}$ necessária para a eliminação do ânion fosfato, na presença daquela quantidade de $\mathrm{SO}_{4}^{2-}$. Procedeu-se conforme escrito na determinação do boro em fertilizantes, usando soluções puras de $\mathrm{H}_{3} \mathrm{BO}_{3}$, de $\mathrm{PO}_{4}^{3-}$ e de SO ${ }_{4}^{2-}$, cujas quantidades estão mostradas no quadro 7 , onde também se encontram os resultados obtidos.

QUADRO 7. - Determinação do $\mathrm{H}_{3} \mathrm{BO}_{3}$, em solução puras, na presença de diferentes quantidades de $\mathrm{PO}_{4}^{3-}, \mathrm{SO}_{4}^{2-} \mathrm{e}^{2} \mathrm{~Pb}^{2+}$.

\begin{tabular}{|c|c|c|c|c|c|c|}
\hline $\begin{array}{c}\mathrm{ml} \mathrm{H}_{3} \mathrm{BO}_{3} \\
\text { adicionado } \\
0,100 \mathrm{~N}\end{array}$ & $\begin{array}{c}\mathrm{mg} \\
\mathrm{H}_{3} \mathrm{BO}_{3} \\
\text { Adicio- } \\
\text { nado }\end{array}$ & $\begin{array}{l}\mathrm{mg} \mathrm{PO}_{4}^{3-} \\
\text { adicionado }\end{array}$ & \begin{tabular}{l}
$\mathrm{mg}$ SO \\
\multicolumn{4}{c}{-} \\
adicionado
\end{tabular} & $\begin{array}{c}\text { ml. Sol. } \mathrm{Pb} \\
\left.\mathrm{NO}_{3}\right)_{2} \mathrm{a} \\
10 \% \\
\text { adicionado }\end{array}$ & $\begin{array}{c}\mathrm{ml} \mathrm{NaOH} \\
0,0285 \mathrm{~N} \\
\text { gastos } \\
\text { na tit. }\end{array}$ & $\begin{array}{c}\mathrm{mg} \\
\mathrm{H}_{3} \mathrm{BO}_{3} \\
\text { det. }\end{array}$ \\
\hline 0 & 0,0 & 0 & 0 & 10 & 0,7 & - \\
\hline 10 & 61,8 & 100 & 120 & 10 & 35,8 & 61,8 \\
\hline 10 & 61,8 & 120 & 120 & 10 & 35,8 & 61,8 \\
\hline 10 & 61,8 & 140 & 120 & 10 & 35,8 & 61,8 \\
\hline 10 & 61,8 & 160 & 120 & 10 & 41,6 & 72,1 \\
\hline 10 & 61,8 & 180 & 120 & 10 & 44,9 & 77,9 \\
\hline 0 & 0,0 & 0 & 0 & 12 & 0,7 & - \\
\hline 10 & 61,8 & 140 & 120 & 12 & 35,9 & 62,0 \\
\hline 10 & 61,8 & 160 & 120 & 12 & 35,9 & 62,0 \\
\hline 10 & 61,8 & 180 & 120 & 12 & 36,4 & 64,7 \\
\hline 10 & 61,8 & 200 & 120 & 12 & 40,2 & 69,6 \\
\hline 0 & 0,0 & 0 & 0 & 15 & 0,7 & - \\
\hline 10 & 61,8 & 180 & 120 & 15 & 35,8 & 61,8 \\
\hline 10 & 61,8 & 200 & 120 & 15 & 35,9 & 62,0 \\
\hline 10 & 61,8 & 220 & 120 & 15 & 36,0 & 62,2 \\
\hline 10 & 61,8 & 240 & 120 & 15 & 37,0 & 64,0 \\
\hline
\end{tabular}


Os resultados mostram que, na presença de $120 \mathrm{mg}$ de SO ${ }_{4}^{2-}, 10 \mathrm{ml}$ de solução de $\mathrm{Pb}\left(\mathrm{NO}_{3}\right)_{2}$ a $10 \%$ eliminam $140 \mathrm{mg}$ de $\mathrm{PO}_{4}^{3-}, 12 \mathrm{ml}$ eliminam $160 \mathrm{mg}$ de $\mathrm{PO}_{4}^{3-}$ e $15 \mathrm{ml}$ eliminam $200 \mathrm{mg}$ de $\mathrm{PO}_{4}^{3-}$. Nos 3 casos a relação existente entre o volume de solução de $\mathrm{Pb}\left(\mathrm{NO}_{3}\right)_{2}$ a $10 \%$ necessária para eliminar fosfato é de aproximadamente $1 \mathrm{ml}$ solução de $\mathrm{Pb}\left(\mathrm{NO}_{3}\right)_{2}$ a $10 \%$ para cada $13,3 \mathrm{mg}$ de $\mathrm{PO}_{4}^{3-} \mathrm{Na}$ determinação em apreço isso equivale a $1 \mathrm{ml}$ de $\mathrm{Pb}\left(\mathrm{NO}_{3}\right)_{2}$ a $10 \%$ para cada $1 \%$ de $\mathrm{P}_{2} \mathrm{O}_{5}$ na amostra de fertilizante.

\section{Avaliação da precisão e exatidão do método.}

Finalmente avaliou-se a precisão e a exatidão do método através de um ensaio de recuperação feito com 5 repetições, empregando as misturas $\mathrm{M}_{1}$ e $\mathrm{M}_{2}$, às quais foram adicionados volumes variáveis de solução padrão de $\mathrm{H}_{3} \mathrm{~B}_{3}$. Os resultados acham-se descritos no quadro 8.

O exame dos desvios padrão das médias e dos coeficientes de variação indica que o método em apreço é dotado de aceitável precisão. $\mathrm{E}$ os resultados apresentados pelo ensaio de recuperação demonstram que o método é dotado de boa exatidão.

\section{CONCLUÓES}

Dos resultados obtidos é possível concluir que:

a) usando para ponto final da titulação o $\mathrm{pH} 8,0$, o íon amônio ( $\mathrm{NH}_{4}^{+}$) interfere na determinação consumindo solução de $\mathrm{NaOH}$. Porém $200 \mathrm{mg}$ de $\mathrm{NH}_{4}^{+}$são completamente eliminados como $\mathrm{NH}_{3}$ por fervura da solução alcalina por 30 minutos.

b) o ânion sulfato influe na precipitação do ânion fosfato com $\mathrm{Pb}\left(\mathrm{NO}_{3}\right)_{2}$. Enquanto que na ausência de sulfato a relação é de 16 mg de $\mathrm{PO}_{4}^{3-}$ para cada $\mathrm{ml}$ de solução de $\mathrm{Pb}\left(\mathrm{NO}_{3}\right)_{2}$ para a completa precipitação do fosfato, em presença de $120 \mathrm{mg}$ de SO ${ }_{4}^{2-}$ são necessários $1 \mathrm{ml}$ de solução de $\mathrm{Pb}\left(\mathrm{NO}_{3}\right)_{2}$ para cada $13,3 \mathrm{mg}$ de $\mathrm{PO}_{4}^{3-} . \mathrm{Na}$ presente determinação isso equivale a $1 \mathrm{ml}$ de $\mathrm{Pb}\left(\mathrm{NO}_{3}\right)_{2}$ para cada cada $1 \%$ de $\mathrm{P}_{2} \mathrm{O}_{5}$ na amostra de fertilizante.

c) adotando o $\mathrm{pH} 8,0$ para o ponto final da titulação, $6 \mathrm{~g}$ de manitol são suficientes para determiar o boro, solúvel em ácido, em fertilizantes. 


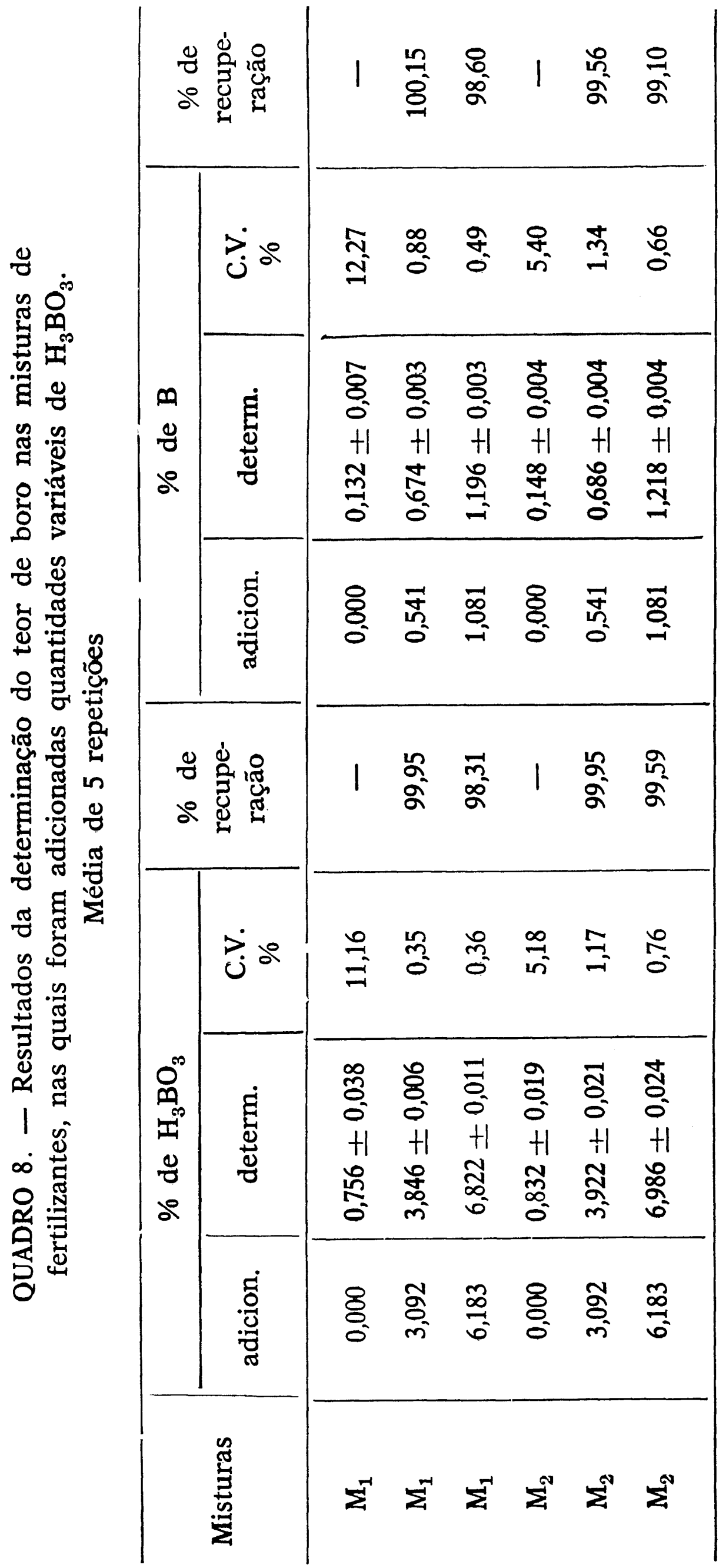


d) o método proposto é dotado de precisão e exatidão satisfatórias.

\section{SUMMARY}

\section{DETERMINATION OF BORON SOLUBLE IN ACID IN FERTILIZERS.}

For the determination of boron soluble in acid, in fertilizers, $6,0 \mathrm{~g}$ of mannitol are sufficient. The influence of the ion $\mathrm{NH}_{4}{ }^{+}$is eliminated by boiling the alkaly solution for 30 minutes. The sulfate ion affect the phosphate precipitation with $\mathrm{Pb}^{2+}$, beeing necessary $1 \mathrm{ml}$ of $10 \% \mathrm{~Pb}\left(\mathrm{NO}_{3}\right)_{2}$ solution for each $1 \%$ of $\mathrm{P}_{2} \mathrm{O}_{5}$ of the sample. The method presents suitable precision and accuracy.

\section{LITERATURA CITADA}

ALCARDE, J. C., R. A. CATANI \& KROLL, 1971. Determinação do boro, solúvel em ácido, em fertilizantes. Anais da ESALQ, 28:287-296.

ALCARDE, J. C., R. A. CATANI \& O. J. SOUZA, 1972. Determinação volumétrica do boro em fertilizantes. Estudos sobre a quantidade de manitol. No perlo dos Anais da ESALQ.

BERGER, K. C. \& P. F. PRATT, 1963. Advances in Secondary and Micronutrient Fertilization. Em: Fertilizer, technology and usage, p. 287-340 Ed. by M. H. Mc Vickar, G. L. Bridger e L. B. Nelson. Soil Science Society of America, Wisconsin, USA.

BORLAND, H., I. A. BROWNLIE \& P. T. GODDEN, 1967. The determination of boron in fertilizers. Analyst, 92:47-53.

OFFICIAL METHODS OF ANALYSIS OF THE A.O.A.C., 1965. 10th ed. p. 24-25. Published by Ass. of Off Anal. Chem., Washington, D.C.

OFFICIAL METHODS OF ANALYSIS OF THE A.O.A.C., 1970. 11th ed., p. 24-25. Published by Ass. of Off. Anal. Chem., Washington, D.C.

RUND, R. C., 1970. Report on fertilizers. J. Ass. Off. Anal. Chem., 53(2): 303-304.

RUND, R. C., 1971. Report on fertilizers. J. Ass. Off. Anal. Chem. 54(2): 247-271.

SCHALL, E. D., 1969. Report on fertilizers. J. Ass. Off. Anal. Chem. 52(2):217-218 e $322-323$.

TAYLOR, D. S., 1949. Determination of borax in mixed fertilizers. J. Ass. Off. Agr. Chem., 32(2):422-430. 